\title{
Agrobacterium-mediated transformation of sorghum: factors that affect transformation efficiency
}

\author{
Carlos Henrique S. Carvalho ${ }^{1}$, Usha B. Zehr ${ }^{2}$, Nilupa Gunaratna ${ }^{2}$, Joseph Anderson², \\ Halina H. Kononowicz ${ }^{2}$, Thomas K. Hodges ${ }^{2}$ and John D. Axtell ${ }^{2}$ \\ ${ }^{1}$ Embrapa Milho e Sorgo, Sete Lagoas, MG, Brazil. \\ ${ }^{2}$ Purdue University, West Lafayette, IN, USA.
}

\begin{abstract}
The results presented in this work support the hypothesis that Agrobacterium-mediated transformation of sorghum is feasible, analogous to what has been demonstrated for other cereals such as rice, maize, barley and wheat. The four factors that we found most influenced transformation were: the sensitivity of immature sorghum embryos to Agrobacterium infection, the growth conditions of the donor plant, type of explant and co-cultivation medium. A major problem during the development of our protocol was a necrotic response which developed in explants after co-cultivation. Immature sorghum embryos proved to be very sensitive to Agrobacterium infection and we found that the level of embryo death after co-cultivation was the limiting step in improving transformation efficiency. The addition of coconut water to the co-cultivation medium, the use of vigorous and actively growing immature embryos and the removal of excess bacteria significantly improved the survival rate of sorghum embryos and was critical for successful transformation. Hygromycin phosphotransferase ( $h p t)$ proved to be a good selectable marker for sorghum. We also found that $\beta$-glucuronidase (GUS) activity was low in most of the transgenic plant tissues tested, although it was very high in immature inflorescences. Although promising, the overall transformation efficiency of the protocol is still low and further optimization will require particular attention to be given to the number of Agrobacterium in the inoculum and the selection of sorghum genotypes and explants less sensitive to Agrobacterium infection.
\end{abstract}

Key words: Agrobacterium tumefaciens, GUS, transformation, sorghum.

Received: October 15, 2002; Accepted: October 21, 2003.

\section{Introduction}

Successful Agrobacterium-mediated transformation has been reported in rice (Aldemita and Hodges, 1996; Hiei et al., 1997; Hiei et al., 1994; Rashid et al., 1996; Toki et al., 1997), maize (Ishida et al., 1996), barley (Tingay et al., 1997), wheat Cheng et al., 1997) and, recently, sorghum (Zhao et al., 2000).

The multiplicity of factors that influence transformation is probably the reason why Agrobacterium-mediated transformation in monocotyledonous plant species has been difficult to achieve (Hiei et al., 1997; Ishida et al., 1996). Several factors are important in transformation, the type and developmental stage of the infected plant tissues, the concentration of Agrobacterium tumefaciens, the composition of the media used for co-cultivation infection and tissue culture, the selectable marker genes used, the type of vector and the plant genotype being among the factors that

Send correspondence to Carlos Henrique S. Carvalho. Embrapa Café, Alameda do Café 1000, 37026-400 Varginha, MG, Brazil. E-mail: carlos@varginha.br. influence transformation (reviewed by Hiei et al., 1997). A critical point in developing an efficient transformation protocol is to find the right combination of the many factors that act together during transformation.

In this paper we discuss several factors that influence transformation efficiency, including the sensitivity of sorghum explants to Agrobacterium infection, type of explant, inoculation method and co-cultivation media. We found that the addition of coconut water to the co-cultivation medium together with the use of vigorous and actively growing immature embryos as explants for infection and the removal of excess Agrobacterium significantly improved the survival rate of explants and were critical for the success of transformation. The sensitivity of immature embryos to Agrobacterium infection was considered by us to be the limiting step to increase transformation efficiency. We also evaluated the use of $\beta$-glucuronidase (GUS) expression as a tool for monitoring transformation events and found that under the conditions of this study GUS expression was higher in specific sorghum tissues. 


\section{Materials and Methods}

\section{Plant material}

Sorghum genotype P898012 was used for most experiments because of its ease for tissue culture, although the genotypes Feterita Gesish (Early Feterita from Sudan), SRN 39 (Striga resistant African line), P967083 (Purdue University developed line), IS2329 (PI\# 217837 Lwalli White), Rio (Sweet sorghum), Sugar drip (Sweet sorghum), B-Wheatland (Commercial B line), RTx430 (Commercial $\mathrm{R}$ line) and Candystripe (Mutable pericarp land race from Sudan) were also evaluated for tissue culture response. Plants cultivated either in greenhouse or in field conditions were used as a source of explants. Seeds containing immature sorghum embryos at the milk stage of endosperm development (usually 1.2 to $2.5 \mathrm{~mm}$ long) were harvested and washed thoroughly with running water for $10 \mathrm{~min}$, surface sterilized for $25 \mathrm{~min}$ in $20 \%$ bleach with approximately $0.1 \%$ Tween 20 , and then rinsed four times with sterile water before embryo extraction. Embryo harvesting and plating onto the tissue cultured medium or inoculation with Agrobacterium were done in the same day. Immature embryos were used as explants for most experiments, although pre-cultured immature embryos cultured in medium I8 (Table 1$)$ for 1 to 5 days, immature inflorescences $(0.5$ to $5 \mathrm{~cm}$ long) and callus derived from immature embryos and inflorescences were also tested. The pre-cultured of immature embryos, co-cultivation and selection after transformation were done in 100x15 mm petri dishes.

\section{Transformation}

We obtained Agrobacterium tumefaciens strain LBA4404, containing the 'super virulent' binary vector pTOK233, from Japan Tobacco Inc. (Hiei et al. 1994) and used this strain in all experiments. The pTOK233 vector contains the virB, virC and virG genes, the hygromycinresistance hygromycin phosphotransferase gene (hpt), a kanamycin-resistance gene (npt) and a gene for $\beta$-glucuronidase (gusA) (Figure 1). Hpt was used as a selectable marker. The Agrobacterium was prepared for inoculation by streaking one loop of the bacterial stock kept at $-70{ }^{\circ} \mathrm{C}$ onto yeast extract peptone (YP) agar (containing $(\mathrm{g} / \mathrm{L})$ yeast extract, 10 ; agar, $8 ; \mathrm{NaCl}, 5$; peptone, 5 ; $\mathrm{pH} 6.8$ ) plates supplemented with $50 \mathrm{mg} / \mathrm{L}$ hygromycin, and incubated at $28{ }^{\circ} \mathrm{C}$ for 3 days. Cultures were collected with a scoop, suspended in inoculation medium (IM, Table 1), adjusted to the required optical density $(\lambda=600 \mathrm{~nm})$ using a Spectronic 21D spectrophotometer (Milton Roy, USA) and used for inoculation within $30 \mathrm{~min}$. In most of the experiments $0.03 \%$ (w/v) Pluronic F-68 was added to IM medium to try to improve transformation efficiency (Cheng et al. 1997).

We studied three different inoculation protocols: 1) Immature embryos were soaked in IM medium containing the Agrobacterium cells for 5 to $10 \mathrm{~min}$, blotted dry with

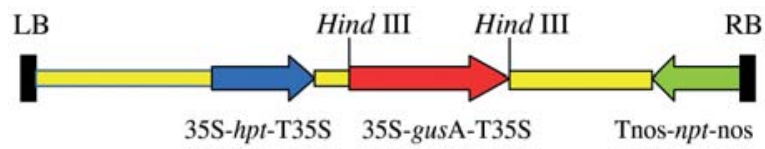

Figure 1 - Schematic diagram of pTOK233.

filter paper to remove excess bacteria and plated on I6As co-cultivation agar in 100x15 mm petri dishes. (Table 1); 2) A drop of the IM medium containing the Agrobacterium cells [I presume this is what you mean.] was applied to individual embryos lying on I6As co-cultivation agar [1]; 3) Immature embryos were placed in a $2 \mathrm{~mL}$ microtube with $1 \mathrm{~mL}$ of IM medium, sonicated for 15 or $30 \mathrm{~s}$ in a Cole Parmer sonicator (Chicago, IL), vortexed for $10 \mathrm{~s}$, allowed to stand for $5 \mathrm{~min}$, blotted with filter-paper and plated onto co-cultivation agar. In one experiment a toothpick and a needle were used to inoculate restricted sectors of the embryos.

In all cases, co-cultivation was allowed to proceed for 2 to 5 days at $25^{\circ} \mathrm{C}$, after which the embryos were transferred to I8+C medium. (Table 1) containing cefotaxime to kill the Agrobacterium and calli proliferation allowed to take place for 6 to 12 days at $27^{\circ} \mathrm{C}$. Some experiments were also carried out to test the effectiveness of the addition of antioxidants and the effects of coconut water (see below). After proliferation calli were transferred to the first selection medium, I8 $+15 \mathrm{H}+\mathrm{C}$ agar (Table 1 ), for two weeks after which they were cut into 1 to $3 \mathrm{~mm}$ pieces and transferred to a second selection medium, $\mathrm{S} 10+25 \mathrm{H}+\mathrm{C}$ agar (Table 1), on which they were grown for 3 to 4 months, being subcultured onto fresh $\mathrm{S} 10+25 \mathrm{H}+\mathrm{C}$ agar every 2 weeks. All callus induction and selection was carried out at $27^{\circ} \mathrm{C}$. The growth of the embryos and Index of Agrobacterium growth during co-cultivation was assessed using a visual index with 0 representing no growth and 5 maximum growth.

Two regeneration protocols were tested: 1) resistant calli were taken from the $\mathrm{S} 10+25 \mathrm{H}+\mathrm{C}$ agar and transferred to $100 \times 25 \mathrm{~mm}$ petri plates containing pre-regeneration medium (PR; Table 1) for two weeks and then to plates of regeneration medium 6 (R6; Table 1) until the plantlets reached about $2 \mathrm{~cm}$ in length when they were transferred to appropriate jars containing fresh R6 medium for further growth under fluorescent light $( \pm 50 \mu \mathrm{E} \mathrm{m} / \mathrm{s})$ at $27^{\circ} \mathrm{C}$; 2) calli with visible immature embryo-like structures were transferred from $\mathrm{S} 10+25 \mathrm{H}+\mathrm{C}$ agar to $100 \times 25 \mathrm{~mm}$ petri dishes containing $\mathrm{R} 8$ medium and cultured in the dark at $25{ }^{\circ} \mathrm{C}$ for $2-3$ weeks. The mature, opaque embryo-like structures were then transferred to regeneration medium 9 (R9; Table 1) and kept under high intensity light $( \pm 120 \mu \mathrm{E}$ $\mathrm{m}^{2} / \mathrm{s}$ ) until plantlet formation. Calli with no visible somatic embryos were first cultured in regeneration medium 7 (R7; Table 1) at $28{ }^{\circ} \mathrm{C}$ for two to three weeks and then transferred to R8 medium and then treated the same as in regeneration protocol 1 , above. 
The regenerated seedlings produced by the protocols described above were transplanted to pots contained a peatmoss mixture, transferred to a greenhouse, and covered with a plastic bag to prevent dehydration. The plastic bags were gradually lifted to decrease humidity, allowing hardening-off of the plants. After one week the plastic bags were removed and the plants allowed to grow to maturity.

\section{Effects of antioxidants, Murashige and Skoog salts and coconut water}

Polyvinylpyrrolidone (PVP, Sigma) and polyvinylpolypyrrolidone (PVPP, Sigma) were both tested for their ability to act as antioxidants and reduce explant browning and death. To test the antioxidant activity of these compounds we conducted other experiments in which we added 0.5 or $1 \%(\mathrm{w} / \mathrm{v})$ PVP or PVPP to the I6As co-cultivation medium along with $0.2 \%(\mathrm{w} / \mathrm{v})$ dithiothreitol (DTT). Following co-cultivation the embryos were cultured for seven days on $\mathrm{I} 8+\mathrm{C}$ medium or $\mathrm{I} 8+\mathrm{C}$ medium supplemented with $0.5 \%$ PVPP and covered with sufficient liquid $\mathrm{I} 8+\mathrm{C}$ me- dium (i.e. $\mathrm{I} 8+\mathrm{C}$ medium without agarose) containing $0.2 \%$ (w/v) DTT to cover the embryos (Perl et al., 1996).

The effects of replacing the MS salts in medium I8 with N6 salts to produce medium I9 (Table 1) were tested in experiments in which medium I8 was replaced by medium I9 for callus induction and cultivation.

Experiments were also made to observe the effects of coconut water by comparing the results produced with medium I8 (containing coconut water) and those produced when medium I8 was substituted by medium I10 (Table 1), which was identical to medium I8 except the coconut water was omitted.

In one experiment, timentin $(150 \mathrm{mg} / \mathrm{L})$ and carbenicillin $(500 \mathrm{mg} / \mathrm{L})$ instead of cefotaxime were used to kill Agrobacterium after co-cultivation.

\section{Electron microscopy}

Scanning electron microscopy (SEM) was used to study embryos inoculated with Agrobacterium. Samples of immature embryos used for transformation were inoculated

Table 1 - Media used for tissue culture and transformation. Media components were autoclaved together at $121{ }^{\circ} \mathrm{C}$ for 20 min , coconut water and antibiotics being added after autoclaving.

\begin{tabular}{|c|c|c|}
\hline Medium code & Use & Composition \\
\hline IM & $\begin{array}{l}\text { Inoculation of Agrobacterium cells } \\
\text { onto embryos }\end{array}$ & $\begin{array}{l}\text { 1/10 Murashige \& Skoog (MS) salts (Murashige \& Skoog, 1962), N6 vitamins (Chu et } \\
\text { al., } 1975 \text { ), } 200 \mu-\mathrm{M} \text { acetosyringone, } 0.03 \% \text { Pluronic F-68 and (g/L) sucrose, 30; glu- } \\
\text { cose, 10; MES, 0.25; 2,4-D, 0.002. pH 5.6 }\end{array}$ \\
\hline I6As & $\begin{array}{l}\text { Co-cultivation of Agrobacterium and } \\
\text { embryos }\end{array}$ & $\begin{array}{l}\text { MS salts, N6 vitamins, } 200 \mu-\mathrm{M} \text { acetosyringone and (g/L) sucrose, } 30 \text {; glucose, } 10 \text {; } \\
\text { agar, } 8 \text {; MES, } 0.25 ; 2,4-\mathrm{D}, 0.002 ; 10 \% \text { coconut water. } \mathrm{pH} \text { 5.6. In some cases } 0.5 \text { or } 1 \% \\
\text { (w/v) Polyvinylpyrrolidone (PVP) polyvinylpolypyrrolidone (PVPP) and } 0.2 \% \text { (w/v) } \\
\text { dithiothreitol (DTT) were added to the medium as antioxidants (see Materials \& Methods) }\end{array}$ \\
\hline I8 & $\begin{array}{l}\text { Growth of immature embryos and cal- } \\
\text { lus proliferation }\end{array}$ & $\begin{array}{l}\text { MS salts, N6 vitamins and }(\mathrm{g} / \mathrm{L}) \text { sucrose, } 30 ; \text { agarose, } 5 \text {; proline, } 3 \text {; asparagine, } 2 \text {; } \\
2,4-\mathrm{D}, 0.002 ; 10 \%(\mathrm{v} / \mathrm{v}) \text { coconut water. } \mathrm{pH} 5.7\end{array}$ \\
\hline I9 & $\begin{array}{l}\text { Growth of immature embryos and cal- } \\
\text { lus proliferation without MS salts }\end{array}$ & Medium I8 but with N6 salts (Chu et al., 1975 ) in place of MS salts \\
\hline I10 & $\begin{array}{l}\text { Growth of immature embryos and cal- } \\
\text { lus proliferation medium without co- } \\
\text { conut water }\end{array}$ & Medium I8 without coconut water \\
\hline $\mathrm{I} 8+\mathrm{C}$ & $\begin{array}{l}\text { Killing Agrobacterium cells and cal- } \\
\text { lus proliferation }\end{array}$ & $\begin{array}{l}\text { Medium I8 plus } 0.25 \mathrm{~g} / \mathrm{L} \text { cefotaxime. In some cases } 0.5 \%(\mathrm{w} / \mathrm{v}) \text { PVPP or } 0.2 \%(\mathrm{w} / \mathrm{v}) \\
\text { DTT was added to the medium as antioxidants (see Materials \& Methods) }\end{array}$ \\
\hline $\mathrm{I} 8+\mathrm{C}+15 \mathrm{H}$ & Selection & Medium I8 plus (g/L) cefotaxime, 0.25 ; hygromycin 0.015 \\
\hline $\mathrm{S} 10+\mathrm{C}+25 \mathrm{H}$ & Selection & $\begin{array}{l}\text { MS salts, B5 vitamins (Gamborg et al., 1977) and }(\mathrm{g} / \mathrm{L}) \text { sucrose, } 30 \text {; agarose, } 5 \text {; } \\
\text { proline, 3; asparagine, 2; cefotaxime, } 0.250 ; 2,4-\mathrm{D}, 0.002 ; \text { kinetin, } 0.0005 . \mathrm{pH} 5.7\end{array}$ \\
\hline PR & Pre-regeneration & $\begin{array}{l}\text { MS salts, B5 vitamins and (g/L) sucrose, } 30 \text {; gelrite, } 2.5 \text {; proline, } 0.4 \text {; cefotaxime, } 0.25 \text {; } \\
\text { asparagine, } 0.2 \text {; indole acetic acid (IAA), } 0.0005 \text {; kinetin, } 0.00025 . \mathrm{pH} 5.7\end{array}$ \\
\hline R6 & Regeneration & $\begin{array}{l}\text { MS salts, B5 vitamins and }(\mathrm{g} / \mathrm{L}) \text { sucrose, } 20 ; \text { gelrite, } 2.5 \text {; proline, } 0.4 \text {; cefotaxime, } 0.25 \text {; } \\
\text { asparagine, } 0.2 \text {; IAA, } 0.001 \text {; kinetin, } 0.0005 . \mathrm{pH} 5.7\end{array}$ \\
\hline R7 & Regeneration & $\begin{array}{l}\text { MS salts, N6 vitamins and (g/L) sucrose, 30; agarose, 5; cefotaxime, } 0.25 ; 2,4-\mathrm{D} 0.00025 . \\
\text { pH } 5.7\end{array}$ \\
\hline R8 & Regeneration & $\begin{array}{l}\text { MS salts, N6 vitamins and (g/L) sucrose, } 60 \text {; agarose, 5.4; cefotaxime, } 0.25 \text {; } \\
\text { IAA, 0.0002. } \mathrm{pH} 5.7\end{array}$ \\
\hline R9 & Regeneration & $\begin{array}{l}\text { MS salts, N6 vitamins and (g/L) sucrose, 20; agarose, } 5 \text {; cefotaxime, } 0.25 \text {; } \\
\text { asparagine, } 0.15 . \mathrm{pH} 5.7\end{array}$ \\
\hline G & Germination & MS salts and (g/L) sucrose, 15; gelrite, 2.5; hygromycin, 0.025. pH 5.7 \\
\hline $\mathrm{G}+\mathrm{H}$ & $\begin{array}{l}\text { Selection of hygromycin resistant } \\
\text { plantlets }\end{array}$ & G medium plus $0.025 \mathrm{~g} / \mathrm{L}$ hygromycin \\
\hline
\end{tabular}


with Agrobacterium and co-cultivated for $32 \mathrm{~h}$ and then vigorously washed five times by vortexing for $15 \mathrm{~s}$ in $0.2 \mathrm{M}$ phosphate-buffer ( $\mathrm{pH} 6.8$ ) containing $0.9 \%$ (w/v) $\mathrm{NaCl}$ to remove bacteria that were not firmly attached. An attachment deficient Agrobacterium (strain At701 chvA:lacZ, provided by Stanton Gelvin, Purdue University) was used as a control to check if the washing procedure removed all non-attached bacteria. Immature embryos were prepared for SEM using a standard protocol for the fixation of biological material.

\section{Inheritance of hygromycin resistance in $T_{1}$ progeny}

To test for the inheritance of the hygromycin phosphotransferase hpt gene we self-pollinated $\mathrm{T}_{1}$ sorghum plants and 20 days after pollination harvested the seeds, surface sterilized them with by washing with $20 \%$ bleach and extracted the immature embryos and plated them onto germination medium $\mathrm{G}$ (Table 1) and allowed them to grow at $28^{\circ} \mathrm{C}$ for 3-6 days. Germinated embryos with active root and shoot growth were then transferred to germination medium containing hygromycin $(\mathrm{G}+25 \mathrm{H}$; Table 1$)$ and the plantlets evaluated for hygromycin resistance 10 days after transfer.

\section{DNA isolation and Southern blot analysis}

Sorghum genomic DNA was extracted from leaf tissue, digested with HindIII and analyzed by Southern hybridization (Gardiner, 1998). A gusA DNA probe was prepared from a BamHI-EcoRI restricted fragment of pBI221 (Clontech) and the hpt DNA fragment probe was obtained from the pHYG plasmid (Thomas Hodges, Purdue University) after restriction digestion with SalI.

\section{Beta-glucuronidase (GUS) expression assays}

We investigated the expression of GUS in actively growing roots, stem sections, young leaves at the rolled stage, mature leaves and young (5 to $15 \mathrm{~cm}$ long) inflorescences from the $T_{1}$ transgenic plant number 687. Samples were divided into two sub-samples, one for histochemical assay and one for fluorogenic assay.

Expression of GUS was assayed by histochemical staining according to (Rueb and Hensgens, 1989) and by the fluorogenic 4-methyl umbelliferyl glucuronide (MUG) assay.

For the fluorogenic assay, $100 \mathrm{mg}$ fresh weight of tissue was homogenized using a pestle and mortar in $1 \mathrm{~mL}$ of extraction buffer (150 mM sodium phosphate, $\mathrm{pH} 7.0$, $10 \mathrm{mM} \mathrm{Na} 2$ EDTA, $10 \mathrm{mM} \beta$-mercaptoethanol, $0.1 \%$ (w/v) Triton X-100, 0.1\% (w/v) N-laurylsarcosine, $25 \mu \mathrm{g} / \mathrm{mL}$ PMSF (Phenylmethylsulfony fluoride). The homogenates were centrifuged at 10,000 rpm for $3 \mathrm{~min}$ and the supernatant (extract) collected and stored on ice until use. A sample of $40 \mu \mathrm{L}$ of the extract was then mixed with $460 \mu \mathrm{L}$ of extraction buffer containing $1 \mathrm{mM}$ MUG and incubated at $37{ }^{\circ} \mathrm{C}$ for $60 \mathrm{~min}$, after which $100 \mu \mathrm{L}$ aliquots were re- moved and mixed with $1500 \mu \mathrm{L}$ of $0.2 \mathrm{M} \mathrm{Na}_{2} \mathrm{CO}_{3}$ to stop the reaction and the fluorescence measured in a fluorometer (Hoefer Scientific).

Protein concentration was determined by using the Bio-Rad Protein Assay reagent (Bio-Rad Laboratories, CA).

The effect of PVPP on GUS activity was determined by homogenizing $100 \mathrm{mg}$ (fresh weight basis) of sorghum leaves with $12.5,25$ or $50 \mathrm{mg}$ (dry weight basis) of PVPP (soaked overnight in extraction buffer) and assaying aliquots of the homogenate fluorometrically as described above. Experiments were also carried out using successively larger aliquots of leaf-homogenate to check whether or not chlorophyll was affecting the fluorometer readings.

As a control, the effect of sorghum leaf extracts on $E$. coli GUS activity was determined using the same fluorometric assay, except that $2.4 \mathrm{U} / \mathrm{mL}$ E. coli GUS was added during sorghum leaf homogenization.

\section{Results}

\section{Tissue culture}

In preliminary experiments, medium I6 (Cai and Butler, 1990) was used for callus induction but in this medium the immature embryos usually produced black pigments which seemed to delay callus growth and also to interfere with the identification of GUS activity. This problem was reduced by adding $3 \mathrm{~g} / \mathrm{L}$ proline and $2 \mathrm{~g} / \mathrm{L}$ asparagine as suggested by Elkonin et al., 1995, to produce medium I8, callus grown in this medium producing much less pigment and growing faster than in medium I6. We tested the replacement of the MS salts in medium I8 with N6 salts (Chu et al., 1975) by producing medium I9 (Table 1) but found that medium I8 produced more embryogenic callus than medium I9 (Table 2) which supports the work of Zhao et al., 2000 who also found that MS-based medium resulted in better embryogenic callus response from immature embryos of P898012.

The addition of coconut water to the medium seemed to increase the percentage of embryos that formed callus, reduced pigment production and improve callus growth (Table 2).

Plant regeneration was easily attained with 2-4 week old callus, but older callus showed much less regenerative capacity. Regeneration Protocol 2 appeared to be more efficient than regeneration protocol 1, although it was not very efficient for the regeneration of callus more than 2 months old.

\section{Effect of donor plant growing conditions}

The tissue-culture response of immature embryos during co-cultivation and callus formation after co-cultivation depended on the growth conditions of the donor plant. Immature embryos isolated from donor plants growing under sub-optimal conditions, such as water stress and 
Table 2 - Effect of coconut water (CW) on callus induction from immature embryos of line P898012 evaluated 14 days after plating. Data from an experiment with six petri dishes with 15 embryos in each dish.

\begin{tabular}{lcccc}
\hline Media (code) & $\begin{array}{c}\text { Embryos that } \\
\text { formed callus (\%) }\end{array}$ & $\begin{array}{c}\text { Embryogenic } \\
\text { callus (\%) }\end{array}$ & $\begin{array}{c}\text { Non-embryogenic } \\
\text { callus (\%) }\end{array}$ & $\begin{array}{c}\text { Pigment } \\
\text { production* }\end{array}$ \\
\hline Murashige and Skoog (MS) salts (I10) & $71.5 \pm 8.2$ & $76.95 \pm 15.0$ & $10.25 \pm 10.4$ & 4 \\
MS + CW (I8) & $87.15 \pm 9.7$ & $84.65 \pm 11.9$ & $2.55 \pm 3.6$ & 4 \\
Chu et al. N6 vitamins + CW (I9) & $79.35 \pm 20.1$ & $69.55 \pm 13.5$ & $8.15 \pm 4.1$ & 5 \\
\hline
\end{tabular}

*Visual scale where 0 corresponds to minimum pigment production or callus growth and 5 is the maximum.

low temperature, did not show any apparent growth during co-cultivation and often died after co-cultivation. Immature embryos isolated from donor plants growing under good environmental conditions responded more promptly to tissue culture, showing some growth during co-cultivation and were less adversely affected by inoculation with Agrobacterium. These embryos also had a better chance of survival after co-cultivation and usually showed bigger spots in the histochemical GUS assays.

\section{Toxic effect of some explants to Agrobacterium}

When cut or injured, immature inflorescence of most sorghum genotypes tested produced toxic compounds that inhibited Agrobacterium growth during co-cultivation. A halo without bacterial growth was often observed around inflorescences and plates having a large inflorescence showed no growth of Agrobacterium. Sorghum is well known for its high content of phenolic compounds, but whether they were responsible for the bactericidal effect was not investigated. This bactericidal effect was also observed in immature embryos, with immature embryos showing good growth under co-cultivation frequently producing black pigments around which Agrobacterium would not grow and no bacterial growth occurred in these areas even when the embryos were removed from the plates. Apparently only embryos in certain stages of development were able to produce substances that prevented bacterial growth, since Agrobacterium was able to grow (as assessed visually) on most embryos sampled. This toxic effect has also been observed in immature maize embryos where it was more pronounced when the embryos were less resistant to infection by Agrobacterium (Schalappi and Holn, 1992).

\section{Sensitivity of immature embryos to Agrobacterium}

A browning phenomenon was observed following co-cultivation of Agrobacterium and sorghum explants, particularly in immature embryos. During co-cultivation immature embryos usually maintained a good appearance, white and smooth. However, when the embryos were transferred to a bacteria-free medium containing cefotaxime but no hygromycin they became brown and shrunk within $48 \mathrm{~h}$ and died. Non-inoculated immature embryos produced normal callus in the presence of cefotaxime, suggesting that cefotaxime was not responsible for the necrotic effect. Furthermore, the browning phenomenon was not diminished by the use of timentin $(150 \mathrm{mg} / \mathrm{L})$ and carbenicillin $(500 \mathrm{mg} / \mathrm{L})$ instead of cefotaxime. The necrotic process was apparently a result of an Agrobacterium-explant interaction, immature embryos from tan plant sorghum genotypes (PP290 and SRN39) showing less browning than immature embryos from red or purple plant sorghum genotypes (P898012 and Feterita) although most of these embryos died after co-cultivation.

Immature embryos observed by SEM during cocultivation were coated with a layer of Agrobacterium cells embedded and trapped in a crust of material probably produced by the Agrobacteria (Figure 2D). This coat could not be removed even after washing by vortexing the immature embryos several times in liquid medium. Almost the whole embryo surface was covered with this material, except the edge, where clumps or individual Agrobacterium cells could be seen attached to each other and to the walls of the embryo cells by a mesh of fibrils (Figure 2C). Some of the
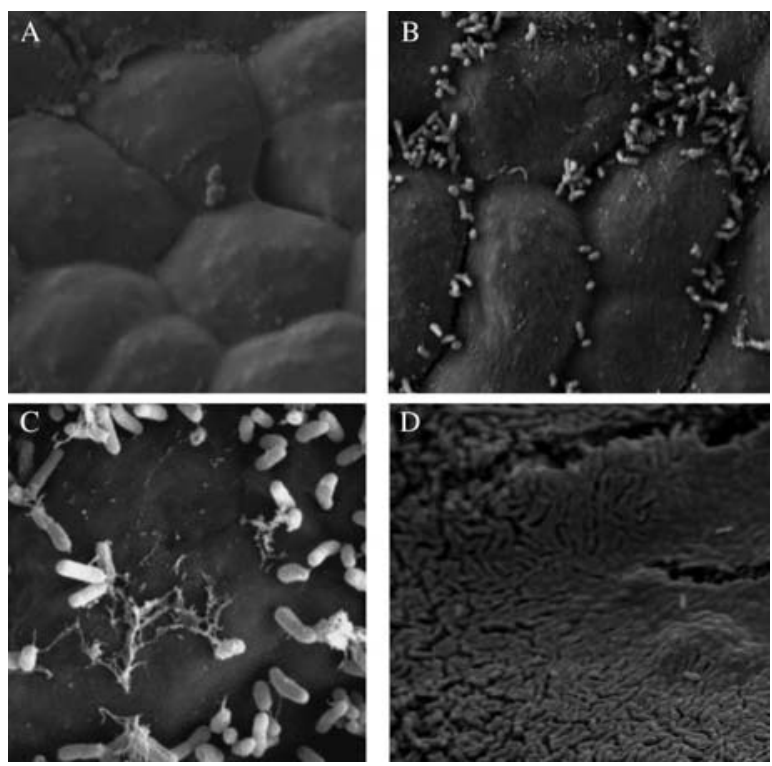

Figure 2 - A: scutelum cells of a sorghum immature embryo before inoculation with Agrobacterium. B: region of the scutelum close to the edge of the embryo, where Agrobacterium cells could be observed spread over the tissue. In most cells Agrobacterium cells are concentrated at the junction of cells. C: detail showing a cluster of Agrobacterium cells attached to each other and to sorghum cells by fibrils. D: immature embryo showing a dense layer of Agrobacterium cells organic substances that coated most of the embryo surface. 
embryos with this coating started to develop a coleoptile instead of forming callus. When embryos were inoculated with a toothpick or needle, even without injuring the embryo, only those sectors that received Agrobacterium became brown, indicating a localized necrotic effect. Reducing the number of Agrobacterium did not eliminate the problem. At $5.0 \times 10^{9}$ colony forming units (cfu)/mLGUS expression was higher but 60 to $100 \%$ of the embryos died after co-cultivation (Table 3 ). With a 10 -fold dilution $\left(5.0 \times 10^{8} \mathrm{cfu} / \mathrm{mL}\right)$ GUS activity was observed only in a very few experiments, although embryo death was still very high. Infection solutions with less than $1.0 \mathrm{x}$ $10^{8} \mathrm{cfu} / \mathrm{mL}$ reduced embryo death to acceptable levels, but no GUS activity was observed. A similar necrotic process elicited by Agrobacterium has been reported in grape (Perl et al., 1996; Pu and Goodman, 1992) and Catharanthus roseus cells (Garner et al. 1996). In grapes it was assumed that necrogenesis was due to a hypersensitive response of the grape cells to the Agrobacterium (Perl et al., 1996).

The addition of PVPP or PVPP+DTT to the inoculation, co-cultivation or post-co-cultivation media slightly reduced browning of immature embryos, but did not improve embryo survival rate after co-cultivation. Moreover, DTT seemed to be toxic to the embryos, which did not produce callus when DTT was added during or after co-cultivation.

Pre-cultured immature embryos and callus derived from immature embryos or inflorescence were less affected by Agrobacterium infection. The more time in tissue culture the explant had before co-cultivation, the higher its survival rate after co-cultivation. Immature embryos cultured in medium I8 for three to five days before co-cultivation and callus which was two to four weeks old showed a much higher survival rate than immature embryos. Most of the pre-cultured immature embryos and callus continued to grow after co-cultivation, although transient GUS expression in pre-cultured immature embryos and callus was rare and usually much lower than that observed in immature embryos. Immature embryos were used for most experiments because they showed higher transient GUS expression than pre-cultured embryos and callus, thus allowing monitoring of the transformation events.

Table 3 - Effect of Agrobacterium concentration on the rate of embryo survival and transient GUS expression. The experiments were conducted using co-cultivation in I6As medium and an average of five replicate experiments with 50 embryos in each experiment.

\begin{tabular}{lccc}
\hline $\begin{array}{l}\text { Number of } \\
\text { Agrobacterium }^{*}\end{array}$ & $\begin{array}{c}\text { Experiments in } \\
\text { which all the em- } \\
\text { bryos died (\%) }\end{array}$ & $\begin{array}{c}\text { Dead embryos } \\
\text { per experiment } \\
(\%)\end{array}$ & $\begin{array}{c}\text { Embryos with } \\
\text { blue spots per } \\
\text { experiment (\%) }\end{array}$ \\
\hline 50 & 40 & $60-100$ & 40 \\
5 & 40 & $60-100$ & rare \\
1 & 20 & $50-100$ & zero \\
0.5 & 10 & $10-40$ & zero \\
0.05 & 0 & $5-25$ & zero \\
\hline
\end{tabular}

*: expressed as colony-forming units $/ \mathrm{mL} \times 10^{8}$.

\section{Effect of Pluronic F-68 on GUS expression}

The addition of $0.03 \%$ Pluronic F68 to the inoculation medium (Cheng, et al., 1997) dramatically increased transient GUS expression by up to 100 -fold (Table 4). Figure $5 \mathrm{~A}$ shows that GUS staining in immature embryos varied from single spots to large patches of blue on the edge and scutelum, although GUS expression in immature embryos was not consistently observed in the same treatment and only about $40 \%$ of the experiments showed some GUS expression. Apparently, the greenhouse and field growth conditions of the donor plants affected transformation efficiency and/or GUS expression. Pluronic F-68 did not increase transient GUS expression in pre-cultured embryos or callus.

\section{Effect of co-cultivation media}

Co-cultivation media significantly affected transient GUS expression and embryo survival after co-cultivation. The use of $3 \mathrm{~g} / \mathrm{L}$ proline and $2 \mathrm{~g} / \mathrm{L}$ asparagine during co-cultivation, which had the best response for callus induction, promoted bacterial overgrowth on the embryos and reduced GUS expression and embryo survival after co-cultivation (Table 5). The use of $1 / 10 \mathrm{MS}$ salts tended to increase the percentage of embryos with blue spots but reduced embryo survival and callus formation after co-cultivation. Although it stimulated the growth of Agrobacterium, the addition of coconut water to the co-cultivation medium promoted a fast embryo response to tissue culture which increased embryo survival. Only immature embryos that showed some growth during the co-cultivation period were able to form callus. The best results were obtained when embryos were immersed in the bacteria inoculation medium for 5 to $10 \mathrm{~min}$, blotted with a filter-paper to remove excess bacteria and co-cultivated on medium I6As containing coconut water. The combination of coconut water in the co-cultivation medium, vigorous, actively growing immature embryos and the removal of excess bacteria significantly improved embryo survival rate and was critical for the success of transformation.

\section{Selection and regeneration of transformed plants}

After co-cultivation the explants were allowed to grow for 6 to 12 days in a medium without hygromycin but with cefotaxime to kill Agrobacterium. This period without selection seemed to help the explants to recover from infec-

Table 4 - Effect of the addition of $0.03 \%(w / v)$ Pluronic F-68 to the inoculation medium on transient GUS expression in immature embryos.

\begin{tabular}{lc}
\hline Treatment & Immature embryos with GUS spots $(\%)^{*}$ \\
\hline $\begin{array}{l}\text { Inoculation medium without } \\
\text { Pluronic F-68 }\end{array}$ & $0-25$ \\
$\begin{array}{l}\text { Inoculation medium with } \\
\text { Pluronic F-68 }\end{array}$ & $0-100$ \\
\hline
\end{tabular}

*Data from eight replicate experiments using 50 embryos per treatment. 
tion and apparently did not affect embryo selection with hygromycin. Hygromycin phosphotransferase (Hpt) seemed to be an acceptable selectable marker for sorghum transformation, since in some experiments putatively transformed calli or transgenic plants resistant to hygromycin were produced from a small number of explants (Events 91, 177: Table 6).

Seven transgenic plants originating from three transformation events were produced in three independent experiments. Five plants grew to maturity as normal fertile plants, while one plant showed stunted growth and stiff leaves and one died in the greenhouse. In two other experiments, calli resistant to hygromycin were produced but no plants were regenerated. Table 6 lists only the experiments where transgenic plants or callus resistant to hygromycin were produced. The transformation efficiency in these experiments ranged from 0.8 to $3.5 \%$, indicating the potential of Agrobacterium-mediated transformation for sorghum. However, the overall transformation efficiency was much lower because the majority of the explants did not survive Agrobacterium infection. Approximately 2000 embryos were inoculated under the same conditions without producing transgenic plants.

\section{Molecular analysis of $\mathrm{T}_{0}$ and $\mathrm{T}_{1}$ transgenic plants}

Stable gene integration was confirmed by Southern blot analysis of $\mathrm{T}_{0}$ and $\mathrm{T}_{1}$ plants. Histochemical and fluo- rogenic assays detected GUS expression in several tissues of stable transformed plants, and the segregation ratio of hygromycin-resistant plants in $T_{1}$ progenies was able to be determined. Although one advantage of Agrobacteriummediated transformation is the tendency to insert a low copy number of transgenes, all three events produced plants with more than one copy of the inserted gene (Figure 3 ).

The segregation ratio of the $\mathrm{T}_{0}$ progeny (Plant 687) was 118 hygromycin- resistant plants to 6 hygromycin susceptible plants (19.6:1), which was close to the expected Mendelian segregation ratio of 15:1 for duplicate genes.

\section{Effect of sorghum leaf extracts on bacterial $\beta$-glucuronidase}

We found that $E$. coli $\beta$-glucuronidase activity was reduced by approximately $15 \%$ when mixed with sorghum leaf extract during homogenization (Figure 4A). Nontransformed sorghum tissue did not show any significant background activity that could affect the detected GUS activity.

In the experiments to determined whether the addition of PVPP during tissue homogenization increased GUS activity in transgenic sorghum we found that the addition of $25 \mathrm{mg}$ of PVPP/100 mg fresh weight of leaves promoted an increase in GUS activity of about 20\% (Figure 4B). Higher amounts of PVPP did not promote any increase in GUS activity and under our conditions it was very difficult to ho-

Table 5 - Effect of co-cultivation media on transient GUS expression in immature embryos, growth of Agrobacterium, embryo growth and the percentage of embryos that formed callus after co-cultivation. Results based on several experiments with 50 embryos in each treatment.

\begin{tabular}{|c|c|c|c|c|}
\hline Media composition & $\begin{array}{l}\text { Immature embryos with at } \\
\text { least one blue spot }(\%) *\end{array}$ & $\begin{array}{l}\text { Index of Agrobacterium } \\
\text { growth during co-cultivation }\end{array}$ & $\begin{array}{l}\text { Index of embryo growth } \\
\text { during co-cultivation }\end{array}$ & $\begin{array}{l}\text { Embryos that formed cal- } \\
\text { lus after co-cultivation }(\%)\end{array}$ \\
\hline Basic medium $(\mathrm{BM})^{1}$ & $19.65 \pm 38.7$ & 3 & 3 & $0-10$ \\
\hline BM made with $1 / 10 \mathrm{MS}$ salts ${ }^{2}$ & $46.25 \pm 35.9$ & 1 & 1 & $0-5$ \\
\hline $\begin{array}{l}\mathrm{BM}+\text { Proline }(3 \mathrm{~g} / \mathrm{L}) \text { and } \\
\text { asparagine }(2 \mathrm{~g} / \mathrm{L})\end{array}$ & 0.0 & 5 & 0 & $0-5$ \\
\hline $\mathrm{BM}+100 \mathrm{~mL} / \mathrm{L}$ coconut water & $37.45 \pm 22.9$ & 4 & 5 & $0-60$ \\
\hline
\end{tabular}

*Average of five experiments. ${ }^{\#} 0=$ none; 5 = maximum.

${ }^{1}$ Basic medium (pH 5.6.) contained MS salts, N6 vitamins, $200 \mathrm{M}$ Acetosyringone and (g/L) sucrose, 30; agar, 8; glucose, 5; 2,4-D, 0.002.

${ }^{2}$ Same as the basic medium except that only $10 \%$ MS salts were used.

Table 6 - Transformation efficiency relative to the experiments in which resistant callus or transgenic plants were produced.

\begin{tabular}{|c|c|c|c|c|c|}
\hline \multirow[b]{2}{*}{ Experiment\# } & \multirow[b]{2}{*}{ Type of explant } & \multicolumn{3}{|c|}{ Number obtained } & \multirow[b]{2}{*}{$\begin{array}{c}\text { Transformation effi- } \\
\text { ciency }(\mathrm{B} / \mathrm{A}, \%)\end{array}$} \\
\hline & & $\begin{array}{c}\text { Inoculated } \\
\text { embryos (A) }\end{array}$ & $\begin{array}{l}\text { Antibiotic resistant } \\
\text { callus }\end{array}$ & $\begin{array}{l}\text { Transgenic } \\
\text { plants (B) }\end{array}$ & \\
\hline 687 & Immature embryo & 120 & 4 & 1 & 0.8 \\
\hline 91 & Immature embryo & 28 & 2 & 1 & 3.5 \\
\hline 189 & $\begin{array}{l}\text { Pre-cultured Immature } \\
\text { embryo ( } 4 \text { days) }\end{array}$ & 128 & 4 & 0 & 0.0 \\
\hline 177 & $\begin{array}{l}\text { Pre-cultured Immature } \\
\text { embryo ( } 3 \text { days) }\end{array}$ & 30 & 3 & 0 & 0.0 \\
\hline 163 & $\begin{array}{l}\text { Pre-cultured Immature } \\
\text { embryo ( } 3 \text { days) }\end{array}$ & 60 & 2 & 1 & 1.7 \\
\hline
\end{tabular}


A

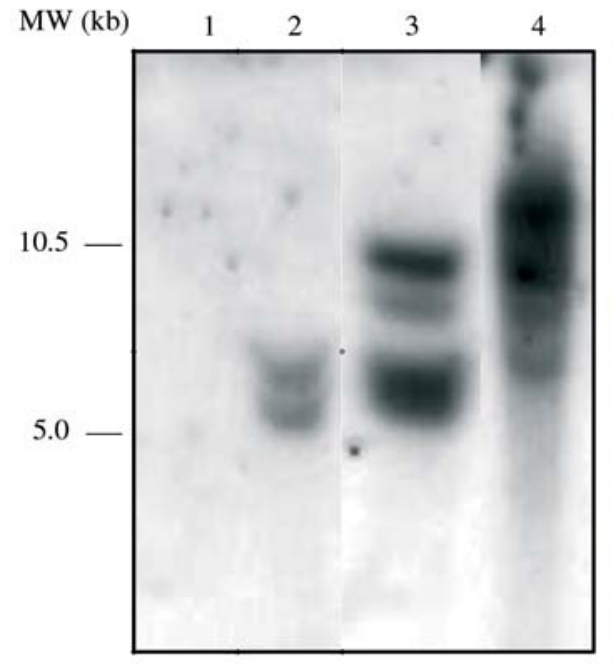

B

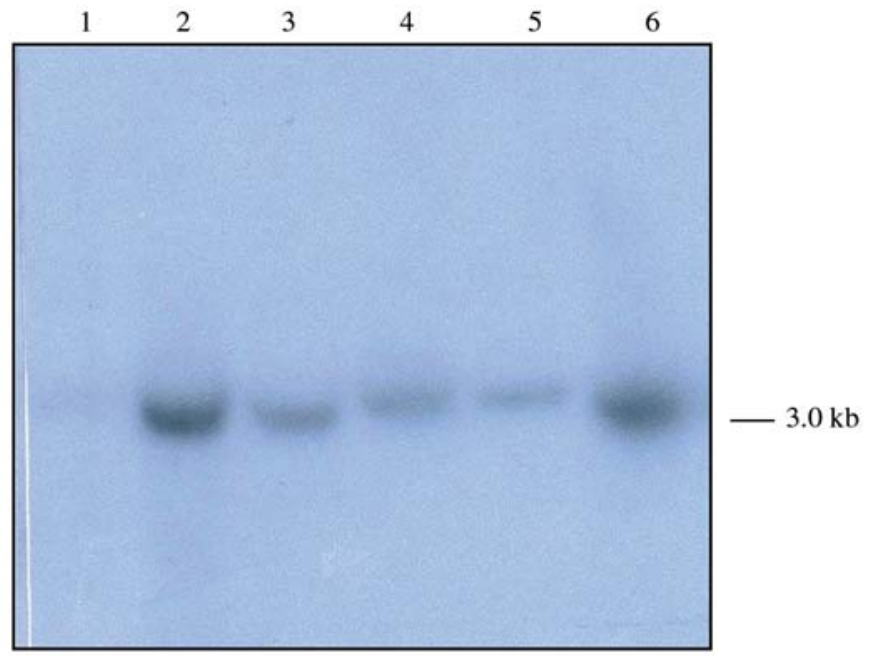

Figure 3 - Southern blot of sorghum genomic DNA isolated from $\mathrm{T}_{0}$ and $\mathrm{T}_{1}$ plants transformed with Agrobacterium tumefaciens LBA4404 (pTOK233). DNA from all plants was digested with HindIII. (A) DNA was hybridized with $h p t$ probe. Lane 1, DNA from $\mathrm{T}_{0}$ non-transformed plant. Lanes 2 , 3 , and 4, DNA from $\mathrm{T}_{0}$ transformed plants 687, 163 and 91, respectively. Single cut with HindIII in the T-DNA shows two copies of the transgene in plant 687 and three in plant 163. (B) DNA was hybridized with gusA. Lane 1, DNA from non-transformed plant. Lanes 2 to 7, DNA from $\mathrm{T}_{1}$ transformed plants derived from plant 687. After digestion with HindIII the expected 3.14-kb fragment was visible.

mogenize the samples when the concentration of PVPP was higher than $50 \mathrm{mg}$ PVPP/100 mg of leaf fresh weight. The slight increase in GUS activity promoted by PVPP indicates that phenolic compounds may have been involved in reducing GUS activity in sorghum.

\section{GUS activity assays in transgenic tissues}

We found that GUS activity was infrequently observed in putatively transformed callus under selection or in callus produced from transgenic plants. Some calli showed small clusters of cells with intense blue staining but the majority of cells did not stain (Figure 5B). Young leaves at the rolled stage usually produced some blue color along the veins or close to the margins but GUS staining was never detected in roots, mature leaves or stems. In general, GUS staining was easily visualized in floral tissues, such as inflorescences, florets and developing seeds (Figure 5). Inflorescences, particularly young ones, showed levels of GUS activity 30 to 60 -fold higher than that found in leaves, stems and roots (Figure 6, vertical bars and pictures). The staining ranged from a strong blue color in inflorescences smaller than $5 \mathrm{~cm}$, up to patches of blue on the rachis nodes (probably regions of active growth) in older inflorescences. The stronger staining in regions of active growth was not due to better stain penetration in these areas, since a longitudinal cut in the inter nodal regions (which would increase stain penetration) did not improve staining. Other floral tissue, such as palea, glume, ovary and seeds also showed GUS staining. These observations suggest that floral tissues, particularly young inflorescences, are better tissues in which to look for GUS activity in putative transformed plants. In mature leaves, stems and roots, GUS activity was detected only by the fluorogenic assay, probably because this method is much more sensitive than the histochemical assay. No blue background was observed in non-transformed sorghum tissues.

Transgenic plant 687 showed GUS activity concentrated in some actively growing tissues such as young leaves and inflorescences, this being particularly evident in inflorescences where GUS activity was detected only in nodal regions undergoing active growth.

\section{Discussion}

The results presented in this work corroborate the assumption that Agrobacterium-mediated transformation of sorghum is certainly feasible, analogous to what has been demonstrated with other cereals such as rice, maize, barley and wheat.

Four factors influenced transformation the most, i.e. sensitivity of immature embryos to Agrobacterium infection, donor plant growing conditions, explant type, and co-cultivation media.

A major problem during protocol development was a necrotic response that the explants developed after co-cultivation. Immature sorghum embryos proved to be very sensitive to Agrobacterium infection and embryo death after co-cultivation was considered a limiting step to improve transformation efficiency. The phenomenon revealed some of the characteristics of a hypersensitivity-like reaction, such as a rapid and localized death of plant cells at the site where Agrobacterium was applied, oxidative burst (browning) and tissue shrinkage. Nevertheless, none of the treat- 

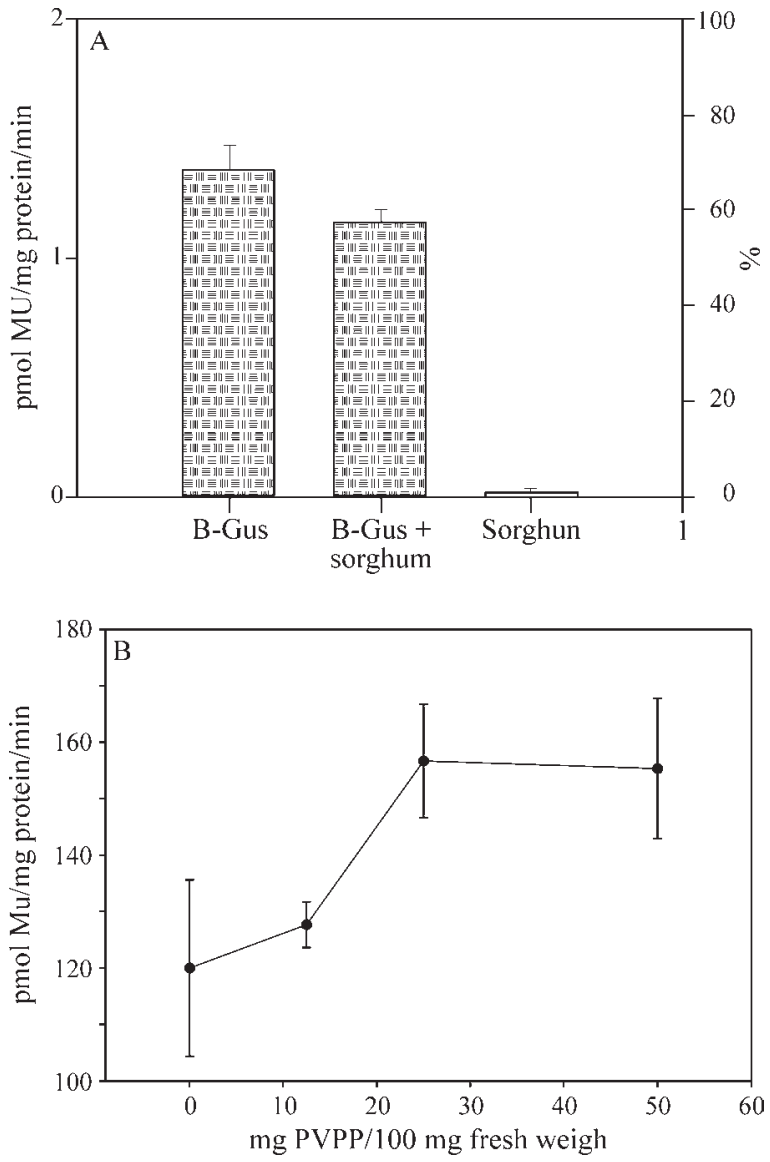

Figure 4 - A: Effect of sorghum leaf extracts of a non-transformed plant on $E$. coli $\beta$-glucuronidase activity when both are mixed together during homogenization. Mean \pm SE for six samples. B: Effect of PVPP concentration on GUS activity in transgenic sorghum leaves. Mean \pm SE for three samples.

ments with antioxidants known to minimize hypersensitivity reaction in other species significantly diminished embryo death, and it is still unclear if embryo death was caused by a hypersensitivity-like reaction.

A large variation in transient GUS expression and immature embryo survival after co-cultivation was found in many experiments under similar conditions. This variation was partly attributable to the influence of the growth conditions of the immature embryo donor plants. Variability in environmental conditions may be associated with reduced plant vigor as a consequence of the sub-optimal lighting and temperature conditions which often occur in greenhouses (Frame et al., 2000). Our results are in agreement with these observations since the best results were obtained with immature embryos collected from more vigorous donor plants.

Transient GUS expression and embryo recovery after infection were also strongly influenced by inoculation conditions and co-cultivation medium. A key point was to maintain the Agrobacterium concentration high enough for
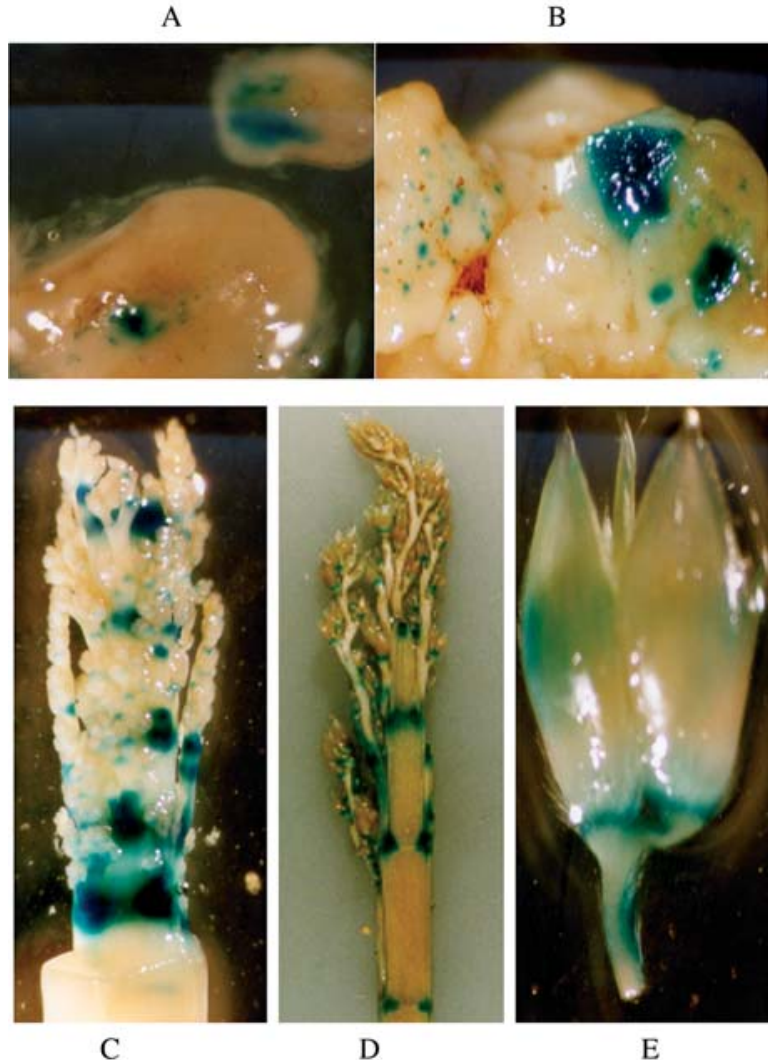

Figure 5 - GUS expression in immature embryos (A), transformed callus (B), young intact inflorescence (C), young inflorescence cut longitudinally (D), and floret before anthesis (E). Note that GUS activity is more visible in tissues in active growth such as nodes of inflorescence.

transformation and inoculation and use co-cultivation conditions that allowed the embryo to response to tissue culture. Under these conditions GUS expression was usually restricted to a few spots on the scutellum. It is possible that the use of a promoter stronger than the CaMV 35 S promoter would enhance GUS activity in sorghum. Similar work also with the genotype P898012 (Zhao et al., 2000) resulted in an average of $60 \%$ of immature embryos with blue spots using the ubiquitin promoter. The ubiquitin promoter has been shown to produce higher GUS expression than the CaMV 35S promoter in other cereals such as maize (Schledzewski and Mendel, 1994), rice (Dong et al., 1991) and barley (Schledzewski and Mendel, 1994).

Coconut water in the co-cultivation and callus induction media improved embryo recovery and callus formation. However, considering that P898012 is a genotype very responsive to coconut water, the use of other genotypes may require different media composition because many genotypes do not respond very well to coconut water (Kaeppler and Pederson, 1996).

Pluronic-F68 dramatically improved transient GUS expression in immature embryos but did not have the same 


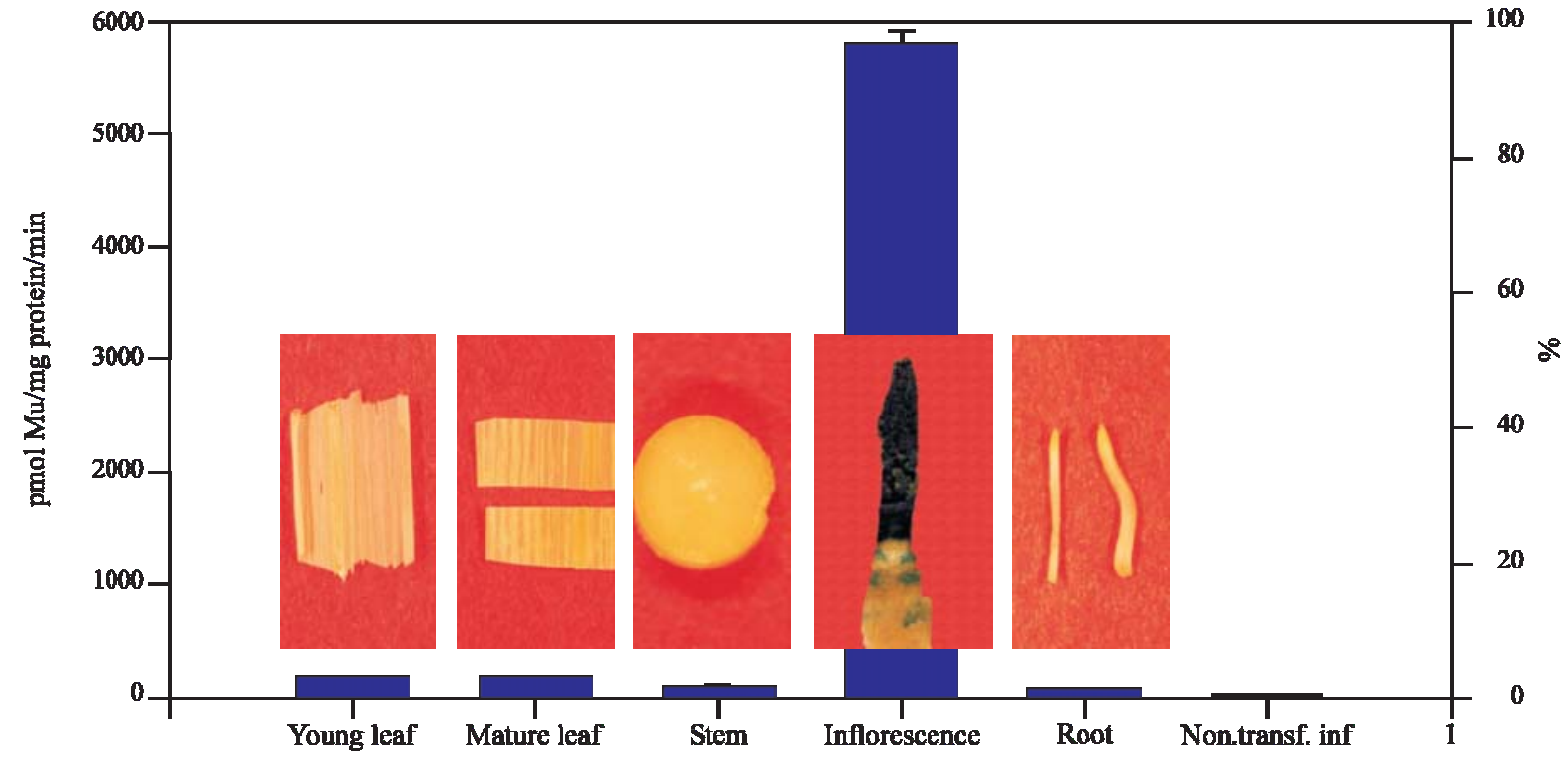

Figure 6 - GUS expression in sorghum tissues of transgenic plant 687. Vertical bars: fluorgenic assay (mean \pm SE for three samples). Pictures: histochemical assay.

effect on pre-cultured immature embryos or callus. This result indicates the usefulness of Pluronic F-68 for immature sorghum embryo transformation, supporting the observations of Cheng et al., (1997) in wheat.

Putatively transformed callus resistant to hygromycin and callus from transgenic plants did not show consistent GUS expression. Some callus pieces showed intense blue staining in localized areas but most of the calli did not stain blue. Thus, GUS expression in callus pieces detected by histochemical assay was not a reliable parameter for assessing transformation. In transgenic plants, GUS activity was stronger in the nodes of young inflorescences, suggesting that this is the best tissue to check for GUS activity. Since the CaMV $35 \mathrm{~S}$ promoter is preferentially expressed in certain tissues (Dong et al., 1991) it may be that this pattern is common for sorghum.

Sorghum leaf extracts reduced E. coli $\beta$-glucuronidase activity by about $15 \%$ and this reduction was associated with the presence of phenolic compounds produced by the leaves. Other plants containing high concentrations of phenolics, such as cranberry, also reduce GUS activity (Serres et al., 1997). However, the 15\% decrease which occurred in our experiments was not enough to fully explain the very low (sometimes undetectable) levels of GUS activity observed in most of the transgenic sorghum tissues analyzed. Low levels of GUS activity seem to be a prevalent characteristic of several sorghum tissues (Battraw and Hall, 1991; Casas et al., 1993 and 1997; Hagio et al., 1991) and may be caused by more than one factor. Besides promoter strength and specificity and the presence of phenolic compounds, the silencing of gus A may also account for the low levels of GUS activity detected.
The hpt locus proved to be a good selectable marker for sorghum. Selection with hygromycin was very efficient and non-transformed calli and seedlings were easily discriminated against in media containing hygromycin.

Although transgenic plants were produced in three experiments, the overall transformation efficiency was quite low. Several other experiments under similar conditions failed to produce transformed plants. Further protocol optimization will require particular attention to inoculum concentration and the use of sorghum genotypes and explants less sensitive to Agrobacterium infection.

\section{Acknowledgments}

We thank EMBRAPA, Brazil, for financial support, D. Sherman from the Electron Microscopy Center at Purdue University for the help and B. Frame from the Maize Transformation Facility at Iowa State University for helpful suggestions on the regeneration protocols.

\section{References}

Aldemita RA and Hodges TK (1996) Agrobacterium tumefaciens-mediated transformation of japonica and indica rice varieties. Planta 199:612-617.

Battraw M and Hall TC (1991) Stable transformation of Sorghum bicolor protoplasts with chimeric neomycin phosophotransferase II $\beta$-glucuronidase genes. Theor Appl Genet 82:161-168.

Cai T and Butler L (1990) Plant regeneration from embryogenic callus initiated from immature inflorescences of several high-tannin sorghums. Plant Cell Tiss Org Cult 20:101-110.

Casas AM, Kononowicz AK, Haan TG, Zhang L, Tomes DT, Bressan RA and Hasegawa PM (1997) Transgenic sorghum 
plants obtained after microprojectile bombardment of immature inflorescences. In vitro Cell Dev Biol 33:92-100.

Casas AM, Kononowicz AK, Zerh UB, Tomes DT, Axtell JD, Butler LG, Bressan RA and Hasegawa PM (1993) Transgenic sorghum plants via microprojectile bombardment. Proc Natl Acad Sci USA 90:11212-11216.

Cheng M, Fry JE, Pang S, Zhou H, Hironaka CM, Duncan DR, Conner TW and Wan Y (1997) Genetic transformation of wheat mediated by Agrobacterium tumefaciens. Plant Physiol 115:971-980.

Chu CC, Wang CC, Sun SC, Hsu C, Yin KC, Chu CY and Bi FY (1975) Establishment of an efficient medium for anther culture of rice through comparative experiments on the nitrogen sources. Sci Sin 18:658-659.

Dong J-Z, Yang M-Z, Jia S-R and Chua N-H (1991) Transformation of melon (Cucumis melo L.) and expression from the cauliflower mosaic virus $35 \mathrm{~S}$ promoter in transgenic plants. Bio/Tech 9:858-868.

Elkonin IA, Lopushanskaya RF and Pakhomova NV (1995) Initiation and maintenance of friable, embryogenic callus of sorghum (Sorghum bicolor (L.) Moench) by amino acids. Maydica 40:153-157.

Frame BR, Zhang H, Cocciolone SM, Sidorenko LV, Dietrich CR, Pegg SE, Zhen S, Schnable P and Wang K (2000) Production of transgenic maize from bombarded type II callus: Effect of gold particle size and callus morphology on transformation efficiency. In Vitro Cell Dev Biol Plant 36:21-29.

Gamborg OL, Shyluk JP, Brar DS and Constable F (1977) Morphogenesis and plant regeneration from callus of immature embryos of sorghum. Plant Sci Lett 10:67-74.

Gardiner JM (1998) UMC Maize RFLP Procedures Manual. Unpublished. (A compilation of procedures with modifications, updated 1998).

Garnier F, Label P, Hallard D and Chenieux JC (1996) Transgenic periwinkle tissues overproducing cytokinins do not accumulate enhanced levels of indole alkaloids. Pant Cell Tissue and Org Cult 45:223-230.

Hagio T, Blowers AD and Earle ED (1991) Stable transformation of sorghum cell cultures after bombardment with DNAcoated microprojectiles. Plant Cell Rep 10:260-264.

Hiei Y, Komari T and Kubo T (1997) Transformation of rice mediated by Agrobacterium tumefaciens. Plant Mol Biol 35:205-218.

Hiei Y, Ohta S, Komari T and Kumashiro T (1994) Efficient transformation of rice (Oryza sativa L.) mediated by Agrobacterium and sequence analysis of the boundaries of the T-DNA. Plant J 6:271-282.
Ishida Y, Saito H, Ohta S, Hiei Y, Komari T and Kumashiro T (1996) High efficiency transformation of maize (Zea mays L.) mediated by Agrobacterium tumefaciens. Nat Biotech 14:745-750.

Kaeppler HF and Pederson JF (1996) Media effects on phenotype of callus cultures initiated from photoperiod-insensitive, elite inbred sorghum lines. Maydica 41:83-89.

Li Z, Upadhyaya NM, Meena S, Gibbs AJ and Waterhouse PM (1997) Comparison of promoters and selectable marker genes for use in Indica rice transformation. Mol Breed 3:1-14.

Murashige T and Skoog F (1962) A revised medium for rapid growth and bioassays with tobacco tissue culture. Physiol Plantarum 15:473-497.

Perl A, Lotan O, Abu-Abied M and Holland D (1996) Establishment of an Agrobacterium-mediated transformation system for grape (Vitis vinifera L.): The role of antioxidants during grape-Agrobacterium interactions. Nat Biotech 14:624-628.

$\mathrm{Pu}$ XA and Goodman RN (1992) Induction of necrogenesis by Agrobacterium tumefaciens on grape explants. Physiol and Mol Plant Pathol 41:241-254.

Rashid H, Yokoi S, Toriyama K and Hinata K (1996) Transgenic plant production mediated by Agrobacterium in Indica rice. Plant Cell Rep 15:727-730.

Rueb S and Hensgens LAM (1989) Improved histochemical staining for $\beta$-glucuronidase activity in monocotyledonous plants. Rice Genet Newsl 6:168-169.

Schalappi M and Holn B (1992) Competence of immature maize embryos for Agrobacterium-mediated gene transfer. Plant Cell 4:7-16.

Schledzewski K and Mendel RR (1994) Quantitative transient gene expression: comparison of the promoters for maize polyubiquitin1, rice actin1, maize-derived $\mathrm{Meu}$ and $\mathrm{CaMV}$ $35 \mathrm{~S}$ in cells of barley, maize and tobacco. Trans Res 3:249-255.

Serres R, McCown B and Zeldin E (1997) Detectable $\beta$-gluguronidase activity in transgenic cranberry is affected by endogenous inhibitors and plant development. Plant Cell Rep 16:641-646.

Tingay S, McElroy D, Kalla R, Fieg S, Wang M, Thornton S and Brettell R (1997) Agrobacterium tumefaciens-mediated barley transformation. Plant J 11:1369-1376.

Toki S (1997) Rapid and efficient Agrobacterium-mediated transformation in rice. Plant Mol Biol Rep 15:16-21.

Zhao Z, Cai T, Tagliani L, Miller M, Wang N, Pang H, Rudert M, Schroeder S, Hondred D, Seltzer J and Pierce D (2000) Agrobacterium-mediated sorghum transformation. Plant Molec Biol 44:789-798.

EditorAssociado: Darcy Fontoura de Almeida 